\title{
EDITORIAL
}

\section{Refugee crisis demands European Union-wide}

\section{surveillance!}

M Catchpole $^{1}$, D Coulombier ${ }^{1}$

1. European Centre for Disease Prevention and Control (ECDC), Stockholm, Sweden

Correspondence: Denis Coulombier (denis.coulombier@ecdc.europa.eu)

Citation style for this article:

Catchpole M, Coulombier D. Refugee crisis demands European Union-wide surveillance!. Euro Surveill. 2015;20(45):pii=30063. DOI: http://dx.doi. org/10.2807/1560-7917.ES.2015.20.45.30063

Article submitted on 12 November 2015 / accepted on 12 November 2015 / published on 12 November 2015

The conflicts in the Middle-East and instability in Libya and some parts of Asia and Africa have resulted in a dramatic influx of refugees to the European Union (EU) in recent years. In the first nine months of 2015, more than 600,000 applications for asylum were filed in the EU [1]. With no prospect of change of the international context in the near future, it is likely that the influx of refugees into the EU will continue and may even increase in coming months.

We have witnessed numerous large displacements of populations in recent years and 'Refugee health' has become an area of concern for national and international, governmental and non-governmental organisations. Much has been learned from responding to these humanitarian crises.

Although refugees are facing a similar spectrum of non-communicable diseases to those experienced by the indigenous population of their countries of origin, trauma and injuries, sexual and reproductive health issues, violence and psychosocial disorders are among the most frequent health problems refugees encounter. Disruption of healthcare delivery systems in their countries of origin and limited access to healthcare during their journey result in the interruption of treatments often required for the control of chronic diseases [2].

Refugee populations entering the EU/European Economic Area (EEA), and particularly children, are at risk of exposure to infectious diseases in the same way as other EU residents, and in some cases may be more vulnerable because of the interruption of public health programmes, notably for immunisation, in their country of origin, as well as through various barriers to access healthcare such as language, culture etc. It is therefore important that they benefit from protection from infectious diseases, including those prevented through routine vaccinations. In addition, these refugees may be at specific risk for certain infectious diseases in relation to their country of origin, countries traversed during their migration, and the conditions they experienced during their mostly difficult journeys.
It is important to note that refugees should not be seen as representing a threat to Europeans regarding infectious diseases, but rather as being themselves vulnerable for such diseases. For example, poor living conditions and close contact in crowded shelters and refugee camps may increase the risk for the spread of lice and/or fleas, which in rare cases can carry diseases such as louse-borne diseases (relapsing fever due to Borrelia recurrentis, trench fever due to Bartonella quintana, epidemic typhus due to Rickettsia prowazekii), murine typhus and mites (scabies). In recent months, sporadic cases of louse-borne relapsing fever (LBRF) have been reported in Belgium, Finland, Germany and the Netherlands among migrants from Eritrea, Somalia and Sudan [3-5]. LBRF is a disease transmitted by body lice that caused major epidemics in the first half of the $20^{\text {th }}$ century in Europe $[6,7]$ and is known to have occurred occasionally among homeless people in recent years, without spreading to the general population [8]. Recent reports from Italy indicate that transmission of LBRF is likely to have occurred in shelters for refugees in the EU, resulting in the risk of cross-border spread as refugees are frequently moving to other countries $[9,10]$. Media are reporting outbreaks of scabies and diarrhoea, notably in Calais, France, in relation to poor housing and hygiene conditions [11].

Meningococcal disease outbreaks have been associated with overcrowding overall and in refugee settings. Contributing factors include sharing dormitories, poor hygiene, and limited access to medical care [12] and that meningococcal carriage rates have been shown to be higher in individuals in overcrowded settings. Most cases are acquired through exposure to asymptomatic carriers [13]. Meningococcal disease has usually been reported in children, but is still a leading cause of both meningitis and sepsis in adolescents, young adults and adults. In addition, overcrowding has been associated with increased transmission of measles, varicella and influenza.

As we are approaching winter, the travelling and living conditions for refugees in transit to Europe or in 
reception centres after their arrival is likely to deteriorate, with even more overcrowding in shelters with insufficient hygiene and therefore increased risk of transmission of communicable diseases. With the start of the influenza season, there is obviously a risk of increased influenza transmission.

Given the numbers and mobility of the refugee populations, the infectious disease risk can only be contained through a coordinated response at the EU level. That includes (i) raising awareness of the risks and types of infection that refugees may have been exposed to and may continue to be exposed to in reception centres, (ii) providing appropriate hygienic and medical countermeasures and (iii) ensuring ready access to medical diagnosis and treatment services. However, such a response will require that Europe has good information on the health situation of the refugees on the move in the EU.

Currently, the basic information that would allow a competent assessment of the situation is not available. The exact number of refugees is not known, and its assessment is hampered because refugees may avoid registration in fear of being sent back [14] and because they continue to move through different European countries. No comprehensive surveillance data is currently being gathered and only sporadic reports by organisations and institutions providing care for these populations are available.

Refugees are not currently a threat for Europe with respect to communicable diseases, but they are a priority group for communicable disease prevention and control efforts because they are more vulnerable.

The scale of the current influx of refugees is inevitably putting pressure on public health systems in frontline receiving countries. Protecting the health of this vulnerable group is complicated further by the potential occurrence of communicable diseases that have not been commonly or widely seen within Europe, creating challenges in terms of recognition and case management. It is vital to ensure that public health authorities have the right information to target resources and provide appropriate measures.

Given these challenges, the European Centre for Disease Prevention and Control (ECDC) will continue to work with its partners in Europe, including public health authorities in the Member States and the European Commission, to strengthen the evidence base guiding prevention and control measures and adding to the current evidence which pinpoint adequate hygiene conditions and vaccination services as the most immediate needs. Strengthening and coordinating surveillance will require continuing efforts to improve the quantity and quality of surveillance data collected through a EU-wide surveillance scheme. It will allow to ensure that interventions aimed at improving health of the refugees are relevant, proportionate, appropriately targeted and coordinated.

Conflict of interest

None declared.

Authors' contributions

Mike Catchpole and Denis Coulombier jointly drafted the editorial.

\section{References}

1. European Asylum Support Office (EASO). Latest asylum trends. Number of applications for international protection in the EU+1. Valetta: EASO; September 2015. Available from: https:// easo.europa.eu/wp-content/uploads/Latest-Asylum-Trendssnapshot-Sept-2015.pdf

2. World Health Organization (WHO). Frequently asked questions on migration and health. Geneva: WHO. [Accessed 11 Nov 2015]. Available from: http://www.who.int/features/qa/88/en/

3. Goldenberger D, Claas GJ, Bloch-Infanger C, Breidthardt T, Suter B, Martínez M, et al. Louse-borne relapsing fever (Borrelia recurrentis) in an Eritrean refugee arriving in Switzerland, August 2015. Euro Surveill. 2015;20(32):21204. DOI: 10.2807/1560-7917.ES2015.20.32.21204 PMID: 26290486

4. European Centre for Disease Prevention and Control (ECDC). Louse-borne relapsing fever in the Netherlands. Rapid risk assessment. Stockholm: ECDC; July 2015. Available from: http://ecdc.europa.eu/en/publications/Publications/louseborne-relapsing-fever-netherlands-rapid-risk-assessment.pdf

5. Cutler S. Refugee crisis and re-emergence of forgotten infections in Europe. Clin Microbiol Infect. 2015 Oct 20. pii: S1198-743X(15)00918-0.

6. European Centre for Disease Prevention and Control (ECDC). Factsheet: Louse-borne relapsing fever. Stockholm: ECDC. [Accessed 11 Nov 2015]. Available from: http://ecdc.europa.eu/ en/healthtopics/emerging and vector-borne diseases/louseborne-diseases/Pages/louse-borne-relapsing-fever.aspx

7. Raoult D, Roux V. The body louse as a vector of reemerging human diseases.Clin Infect Dis. 1999;29(4):888-911. DOI: 10.1086/520454 PMID: 10589908

8. Brouqui P, Stein A, Dupont HT, Gallian P, Badiaga S, Rolain JM, et al. Ectoparasitism and vector-borne diseases in 930 homeless people from Marseilles. Medicine (Baltimore). 2005;84(1):61-8. DOI: 10.1097/01.md.0000152373.07500.6e PMID: 15643300

9. Ciervo A, Mancini F, di Berenardo F, Giammanco A, Vitale G, Dones $\mathrm{P}$, et al. Louse-borne relapsing fever in young migrants, Sicily, Italy, July-September 2015. Emerg Infect Dis. 2015;22(1). Ahead of print.

10. Lucchini A, Lipani F, Costa C, Scarvaglieri M, Balbiano R, Carosella S, et al. Louseborne Relapsing Fever among East African Refugees, Italy, 2015. Emerg Infect Dis. 2015;22(2). Ahead of print. DOI: 10.3201/eid2202.151768

11. Capon F. Migrants Suffering From Gangrene, Scabies at Calais Camps. Newsweek; July 2015 Available from: http://europe.newsweek.com/ migrants-suffering-gangrene-scabies-calais-camps-331338

12. Lam E, McCarthy A, Brennan M. Vaccine-preventable diseases in humanitarian emergencies among refugee and internally-displaced populations. Hum Vaccin Immunother. 2015;11(11):2627-36. DOI: 10.1080/21645515.2015.1096457 PMID: 26406333

13. Deutch S, Labouriau R, Schønheyeder HC, Ostergaard L, Nørgård B, Sørensen T. Crowding as a risk factor of meningococcal disease in Danish preschool children: a nationwide population-based case-control study. Scand J Infect Dis. 2004;36(1):20-3

14. The Balkans. Asylum seekers, migrants and refugees in transit. Geneva: ACAPS. [Accessed 11 Nov 2015]. Available from: http:// acaps.org/img/documents/b-acaps-bn-balkans-asylumseekers-migrants-refugees-in-transit-6-nov-2015.pdf 